\title{
ICT in mathematics education: an HLM analysis of achievement, access to and use of ICT by African Middle School Students
}

\author{
Catherine Namome ${ }^{1}$ (D) Maglin Moodley ${ }^{2}$
}

Received: 4 May 2021 / Accepted: 3 August 2021 / Published online: 1 September 2021

(c) The Author(s), under exclusive licence to Springer Nature Switzerland AG 2021

\begin{abstract}
This study examined the influence of access to and frequent use of information and communication technology (ICT) in school and home settings on achievement in mathematics for Grades 8 and 9 African students. A large-scale international database, that of the 2015 Trends in International Mathematics and Science Study was used and hierarchical linear models were employed to examine school- and studentlevel variables. Findings showed that student access to ICT during a lesson was significant and a positive predictor for student learning outcomes in mathematics, while teacher integration of ICT into pedagogy as a mediating factor had a negative association. Student-level ICT predictors, for example access to ICT at home, had a positive association with student learning outcomes in mathematics, while intensity of student ICT use was a negative predictor; this applied even after controlling for age, gender, and educational resources at home.
\end{abstract}

Keywords TIMSS $2015 \cdot$ Mathematics achievement $\cdot$ ICT access $\cdot$ ICT use

\section{Introduction}

The COVID-19 pandemic continues to redefine the way in which schools conduct teaching and learning. While the global schooling system has been greatly disrupted, the impact of the pandemic on the African schooling system has been exceedingly telling. Most African schools have been closed for prolonged periods, yet they are not equipped with information and communication technologies (ICT) to enable

Catherine Namome

cnamome@hsrc.ac.za

1 Inclusive Economic Development Research Programme, Human Sciences Research Council, 134 Pretorius Street, Arcadia, Pretoria 0002, South Africa

2 Department of Science and Technology Education, Faculty of Education, University of Johannesburg, Auckland Park Kingsway Campus, Auckland Park, Johannesburg 2006, South Africa 
them to continue with teaching and learning during such disruptions. Africa needs a major impetus for education-based ICT innovation, reform and expansion for the continent's education system.

Some efforts are under way to encourage the introduction and integration of information and communication technologies (ICTs) into schools, but the pace remains slow. Examples include initiatives such as ICT Transforming Education in Africa (UNESCO 2018), One Laptop per Child (Fajebe et al. 2013), the Africa Digital Schools ICT project (Agyei and Voogt 2011), the EdQual project (Rubagiza et al. 2011) and the NEPAD e-Schools Initiative (Adeosun 2010).

Despite these initiatives, achievement in mathematics among African students has stagnated with little improvements. Figure 1 shows average mathematics achievement scores for African countries that participated in the Trends in International Mathematics and Science Study (TIMSS). South Africa and Egypt have shown some positive changes, with South Africa having earned 37 average score in the past 10 years while for Morocco the changes are minimal (17 average score). Botswana had a decline in mathematics performance in 2015. These scores remain low compared to countries in Asia or Europe.

Theory and literature suggest that student background, school and home access to and frequency of ICT use are among important determinants of educational performance (Eickelmann et al. 2012; Hu et al. 2018; Hudson and Porter 2010; Skryabin et al. 2015; Spiezia 2011). In this paper, we test the robustness of these previous findings in an African context by constructing and estimating an education production function for Africa. The paper focuses on the relationship between mathematics achievement, school/home access to and frequency in use of ICT resources and student background characteristics. Four African countries participated in TIMSS 2015, that is, Botswana, Egypt, Morocco and South Africa are part of the current study.

A major contribution of this study to the literature relates to the influence of access to ICT and use of ICT has on student performance in an African context. The current study sheds light on the complex influences of access to ICT and its use

-2011 $\quad 2015 \square 2019$

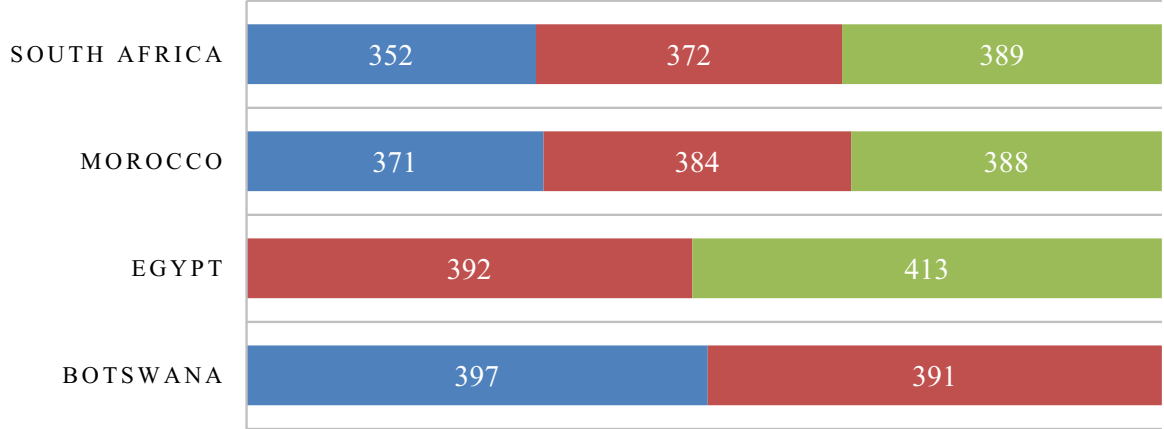

Fig. 1 TIMSS average mathematics achievement scores for African countries 
by investigating a wide spectrum of students in Africa; therefore, the findings from this study are better suited to generalisation. In addition, by estimating hierarchical linear models (HLMs), different mediating variables are controlled at different levels and the findings are thus significant for better understanding how access to ICT and its use influences student academic achievement in mathematics.

\section{Research objective}

The general research objective of this study was to determine if access to and frequency of use of ICT resources influenced the academic achievement of Grades 8 and 9 African students in mathematics. Within the context of this study, the terminology 'access to' refers to the availability of ICT resources at both the school and home settings, while 'frequency of use' refers to their rate of use of these ICT resources they have access to. The study was guided by the following research questions. Main research question: How does access to and frequency of use of ICT resources influence the academic achievement in mathematics of Grades 8 and 9 African students?

Sub research questions:

1. Is student ICT access at home and school related to their mathematics performance at school?

2. What student background factors mediate the association between access to and frequency of use of ICT with mathematics achievement?

3. How does student frequency in use of ICT resources at school/home influence student mathematics achievement?

\section{ICT development in Africa and ICT in education}

An African teacher is often characterised as the sole source and sender of knowledge through "chalk-and-talk" (Barakabitze et al. 2015). This trajectory, however, is steadily changing. African governments are aspiring to become information societies, in part to be equal partners in the global knowledge-based economy (Ponelis and Holmner 2015). The International Telecommunication Union (ITU) is the United Nations' agency for ICTs. In 2020, the ITU released Measuring digital development: Facts and Figures, which reported that in Africa, 29\% of Africans are using the internet, and $28 \%$ of African urban households have access to the internet at home, which is 4.5 times higher than that in rural areas (6\%). A similar picture is reported in terms of computer access (International Telecommunication Union 2020).

The ICT Development Index (IDI), also produced by ITU, is a measure that benchmarks and compares developments in ICT between countries. The IDI scores remain low for most African countries. According to the 2015 IDI, Botswana scored 3.82, Egypt 4.40 and Morocco 4.47, with South Africa relatively higher at 4.90 
(International Telecommunication Union 2015). The UNESCO Institute for Statistics published a comparative analysis for basic e-readiness in schools for sub-Saharan Africa (UNESCO-UIS 2015). In terms of computer density (student to computer ratio) it was reported that computers were unevenly spread, often being concentrated in the relatively few schools with basic ICT infrastructure. Furthermore, it was noted that computers were often stored and unused, for reasons which include lack of teacher training in ICT or anxiety related to computer use.

In Botswana and South Africa, it is reported that student to computer ratios in primary education are 40:1 and 90:1, respectively. Computers are more frequently available for secondary education, with Botswana having a ratio of 17:1 for upper secondary and 15:1 for lower secondary education (UNESCO-UIS 2015). South Africa, with a combined secondary education, has a ratio of 54:1 (UNESCO-UIS 2015). For Egypt, the student (pupil) to computer ratio is 48:1 (UNESCO-UIS 2016).

This high student to computer ratio often hinders meaningful learning. Computer density remains very low in a number of African countries; for example, UNESCOUIS (2016) reported that $49 \%$ of schools in Egypt had internet connectivity. Data on ICT remain a challenge, and we could not find relatable data on student to computer ratios for countries like Morocco. Internet access to support online learning ranges substantially across countries, and education ministries often have little or no control over internet connectivity in schools (UNESCO-UIS 2015). Data on internet usage and computer-assisted instruction in primary and secondary schools were not available for the countries of interest.

\section{Literature review-ICTs and its influence on student academic achievement}

In education, literature shows that ICTs are effective in addressing educational needs (Skryabin et al. 2015). This has increased research on the causal and relational/associations of ICTs and education attainment. Two broad research areas have emerged: the first focuses on the causal relationship, essentially addressing the effectiveness of ICT resources on student academic achievement; the second considers the influence ICT access and use has on student academic achievement, often using crosssectional survey data.

Angrist and Lavy (2002) analysed how a computerised policy affect some schools that received computers and control schools that did not. Their findings showed that after controlling for observable characteristics, use of educational computers did not have a positive effect on students test scores. In fact, the relationship between computer use and mathematics achievement in Grade 4 was negative and significant. In contrast, Banerjee et al. (2007) analysed the outcome of a randomised policy in India that aimed at improving mathematical skills, and found a positive impact on achievement scores. A similar positive impact was reported by Barrow et al. (2009), who randomly assigned students to a computer-aided instruction programme and reported higher scores in pre-algebra and algebra tests compared to students not on the programme. 
Despite the potency of causal studies, other studies have tended to focus on largescale cross-sectional survey data to examine relationships between the access to ICT and its use and student academic achievement. For example, Wittwer and Senkbeil (2008) analysed the relationship between computer use at home and student achievement using the 2003 Programme for International Student Assessment (PISA). They find that students' access to a computer is not linked to performance in mathematics, but a positive influence on mathematics was observed for a small group of students who used the computer in a self-determined way where they engaged in problemsolving activities.

Eickelmann et al. (2012) uses TIMSS 2007 data and applies a multi-level approach to conduct an analysis examining whether use of ICT in mathematics education in primary schools predicts mathematics achievement in Asia, Oceania and Europe. Their findings indicate a significantly positive association between computer use at home and mathematics achievement. A similar relationship was identified for computer use at school in Singapore and Australia, but there was no relationship with student achievement in Germany.

Zhang and Liu (2016) investigated trends in the relationship between ICT use and students' mathematics and science achievement from five waves of the PISA data. Their findings indicate that the relationships between types of ICT use and mathematics achievement were negative in the long term when controlling for students' socio-economic status. What emerges from this review is that there is mixed evidence supporting the hypothesis of a relationship of access to ICT, use of ICT and students' mathematics achievement, from both causal and large-scale cross-sectional survey studies.

However, is this relationship different within the African context? According to Bray and Tangney (2017), the positive relationship between student achievement in mathematics and the use of ICT would only be achieved through a combination of appropriate pedagogy and ICT, and their study further reiterates that positive achievement in mathematics through the use of ICT allows for the creation of realistic problem-solving contexts. This view is further emphasised by Graham et al. (2020) who support the views of Wittwer and Senkbeil (2008) and Bray and Tangney (2017), by highlighting that the data from the South African component of the TIMSS 2015 shows that the use of ICT in teaching can assist in improving the achievement of students.

However, their study also highlighted that for student achievement to improve, specific teacher factors like attitude, confidence and pedagogical understanding is essential. In a study conducted in Botswana, Tsayang et al. (2020), found that ICT resources were only used for specific subjects and furthermore noted that ICT use does influence educational outcomes and that the use of technology helps students to better understand and retain subject content while improving their attitude towards learning. These findings were also correlated by Ndlovu et al. (2020), who found that ICT if used effectively can influence student mathematics achievement. The findings showed that South African preservice teachers identified the following key factors as being essential for using ICT to influence achievement, these included: mathematics teachers must adjust to the demands and challenges of the digital era; belief in a changing mathematics teacher identity; mathematics teachers must have 
strong competencies to use ICT in their classroom and there should be adequate resources and proper planning.

According to Garegae (2015), Botswana's performance in TIMSS 2003 and 2007 studies confirm low performance of schools in Botswana, as it was one standard deviation below the international mean. Various studies (Garegae 2015; Tsayang et al. 2020 and Ndlovu et al. 2020) affirm that the use of ICT in teaching and learning can influence student achievement levels. However, Graham et al. (2020) and Umugiraneza et al. (2018) noted that even though schools within the African context may be provided with the necessary resources and teachers are technically upskilled, it does not guarantee the use of ICT in teaching, but that a series of factors eventually influences the use of ICT in teaching and learning.

Berrado et al. (2009) investigated the influence of ICT in student achievement in mathematics and the sciences in Morocco and their findings showed that the influence of ICT was not consistent across all the schools, but that socio-economic and school environmental factors greatly influenced student achievement. Hence from the literature it becomes very evident that while there is a general consensus that ICT can influence teaching and learning and ultimately student achievement, there is also a school of thought in the literature that contends that there are factors both intrinsic and extrinsic to students and teachers that influences the use of ICT in teaching and learning.

\section{Conceptual framework and the econometric model}

Before examining the influence of access to and usage of ICT resources on student achievement, assessing the conceptual groundwork of how achievement could be influenced is important. We follow Hanushek (1979) and think of the educational system as an education production process (Carrillo et al. 2011; Erdogdu and Erdogdu 2015; Lamdin 1996). Conceptually, we then define an education production function as Eq. (1):

$$
Y_{i t}=f\left(B_{i t}, S_{i t}, A_{i t}, I_{i t}\right)
$$

where for student $i, Y_{i t}$ is the mathematics achievement test scores measured at time $t, B_{i t}$ is a vector of student background characteristics, and $S_{i t}$ is a vector of school ICT inputs. Vectors $A_{i t}$ and $I_{i t}$ denote student academic abilities, which could change over time. How then can access to ICT and its use in school and home settings influence mathematics achievement? We think there are at least two ways in which access to ICT and its use can have an influence on students' mathematics outcomes. Firstly, in school settings, provision of ICT to students through computer labs and software and training teachers in ICT professional development can improve school assets and teaching quality, which can potentially improve learning outcomes. Secondly, student exposure and access to ICT at home facilitates completion of their school homework and always being informed about their subject content. This may shift the cognitive abilities of students, allowing them to learn faster (Carrillo et al. 2011). 
Empirically, we measure the influence of ICT access and usage by estimating a linearised form of Eq. (1), which is implemented using hierarchical regressions. The equation is written as Eq. (2):

$$
Y_{i}=\alpha+f\left(T_{i}, S_{i}, \mathrm{ICT}_{i}\right)+\varepsilon_{i j}
$$

where $Y_{i}$ is the test score of student $i, T_{i}, S_{i}$ and $\mathrm{ICT}_{i}$ are vectors of variables that measure teacher-, student- and ICT-related characteristics of teachers, and $\alpha$ is the intercept. $\varepsilon$ is the iid disturbance term that captures all of the unobserved factors that could influence student performance, and is specified as follows:

$$
\varepsilon_{i j}=\mu_{i}+\theta_{j}+v_{i j}
$$

where $\mu$ and $\theta$ represent student time-invariant unobserved factors. If we estimated Eq. (1) by OLS, this could yield biased estimates, especially when unobserved factors are correlated with the variables in the ICT vector. This may be the case when neither teachers nor students are randomly distributed across schools (and across classes within schools), or when the use of ICT teaching practices is influenced by teachers' unobserved characteristics that could in turn influence student performance (Comi et al. 2017).

Since students are nested within classes, using HLMs is appropriate for the analysis. Hierarchical linear modelling is a form of ordinary least squares regression that analyses variance in the outcome variable when the predictor variables are at different levels (Woltman et al. 2012). In the present analysis, students nested in a classroom share variance according to their teachers and classrooms (Woltman et al. 2012). Thus, HLM accounts for the shared variance in hierarchically structured data such as that gained from the TIMSS. The technique estimates lower-level slopes (for example, student level) and their influence in estimating higher-level outcomes (classroom level) (Goldstein 2011; Hox et al. 2017; Woltman et al. 2012). Hence, with TIMSS data HLM would have an advantage over other regression analyses in dealing with estimation problems, for example aggregation bias or under-estimated standard errors (Skryabin et al. 2015) as cited in Lee (2000).

Typically, the analysis begins with null models that determine the extent to which observations within schools are correlated. The intraclass correlation coefficient (ICC), which indicates the size of the clustering effect, is then calculated to estimate the degree to which between school variances were represented in the total variation of the student mathematics scores:

$$
Y_{i j}=\gamma_{00}+e_{i j}+r_{i j}
$$

where $Y_{i j}$ is the mathematics scores for student $i$ in school $j, \gamma_{00}$ is the grand mean of mathematics scores for all participating schools, $e_{i j}$ is the residues for student $i$ in school $j, r_{0 j}$ is the residues for school $j$.

Then prediction of variables from the student level (access to ICT, frequency of use, school-related variables) are included sequentially as in Eq. 4. Hence the final HLM model is written as follows: 


$$
Y_{i j}=\gamma_{00}+\pi_{u j} \text { Student }_{i j}+\beta_{v j} \operatorname{School}_{0 j}+e_{i j}+r_{0 j}
$$

where $\pi_{u j}$ is the slope of $U$ student-level variables for student $U$ in school $j, \beta_{v j}$ is the slope of $V$ school variables for school $j$.

\section{Methods and data}

\section{Sample}

This study utilises data from TIMSS, a large-scale assessment undertaken by the International Evaluation Assessment (IEA). TIMSS surveys use systematic probability proportional to size (PPS) sampling techniques which match with the hierarchical nature of the clustered sampling units. Multistage cluster sampling is used, together with jack-knife replication technique of 75 replicates for estimating the sampling error.

The sample for this study was drawn from the TIMSS 2015 dataset which was released in December 2017. Four African countries participated in TIMSS 2015: Botswana, Egypt, Morocco and South Africa. The sample consists of Grades 8 and 9 students; Botswana and South Africa assessed Grade 9 students, while Egypt and Morocco had Grade 8 students. In this sample we use student and teacher data, which includes 39,372 students and 1007 teachers.

In the student sample, girls account for $50.07 \%$ and boys for $49.93 \%$ (Table 1). The age range of the students was between 9 years and 4 months, and 19 years and 9 months. In addition, the total percentage of students with ICT access at home was $40.39 \%$ and at school was $15.79 \%$. The percentage was much lower for students who had access to ICT both at home and at school (8.42\%).

\section{Data analysis}

\section{Variables and variable (re)coding}

A two-level HLM model was developed to examine the relationship between mathematics achievement and students' access to and use of ICT. Mathematics scores were used as the dependent variable. TIMSS assessments used a rotated-booklet design for testing students' mathematics skills. This implies that each student only completed a small section of the entire set of test items. Thus, TIMSS allocated a score to each student, and this score was comparable across all students that participated in the assessment. TIMSS computed five plausible values (PVs) of mathematics to measure students' performance (see Table 2). This study followed the recommendations for addressing PVs in large assessments, considering all five PVs simultaneously as the representation of each participating student. The five PVs are a representation of the range of abilities that a student could attain if she/he had completed the entire test, considering the measurement error in the test (Willms and Smith 2005) as cited in Skryabin et al. (2015). 


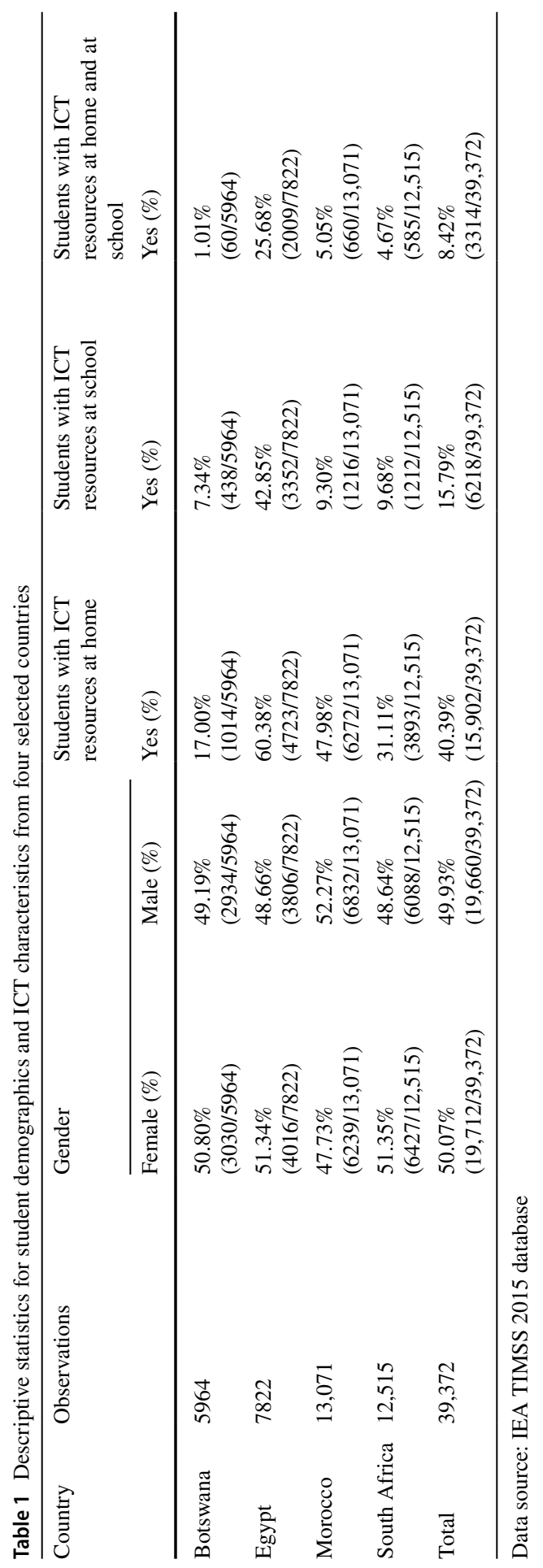


Table 2 Descriptive statistics for plausible values in mathematics

\begin{tabular}{llllll}
\hline Variable & Description & Mean & Std dev & Minimum & Maximum \\
\hline BSMMAT01 & Plausible value 1 of mathematics score & 385.82 & 85.79 & 64.29 & 725.45 \\
BSMMAT02 & Plausible value 2 of mathematics score & 385.33 & 86.59 & 48.46 & 744.61 \\
BSMMAT03 & Plausible value 3 of mathematics score & 384.63 & 87.17 & 52.10 & 774.29 \\
BSMMAT04 & Plausible value 4 of mathematics score & 383.52 & 87.22 & 16.89 & 778.05 \\
BSMMAT05 & Plausible value 5 of mathematics score & 384.67 & 86.81 & 58.75 & 732.33 \\
\hline
\end{tabular}

Data source: IEA TIMSS 2015 database. $N=39$ 372. The dependent variable is students' mathematics literacy, reflected by students' mathematics scores in the TIMSS assessment test

School-level variables The school level consists of three primary variables: students' access to instructional computers, teachers' ICT integration in a lesson, and teachers' job satisfaction. The students' access to instructional computers index was calculated from three item responses: (a) Each student has a computer, (b) The class has computers that students can share, and (c) The school has computers that the class can use sometimes. The index for teacher ICT integration in a lesson was computed on the basis of four items that measured teachers' perceptions of how they use ICT in a lesson: (a) I let students to use computers to explore subject, principles and concepts, (b) I let students to use computers to practice skills and procedures, and (c) I let students to use computers to process and analyse data. These indices were constructed using principal component analysis, and both had one component each. Higher scores indicated better access to instructional computers in the case of students, and better use of ICT by teachers. The third school variable, used as a controlling variable, was teacher job satisfaction, which is an IEA TIMSS indicator.

Student variables The student-level variables included demographic and ICT access-/use-related variables. Three variables that indicated student background were used as controlling variables in the models: home resources, gender ( $1=$ 'male', $0=$ 'female') and students' age. On the TIMSS student questionnaire, students were asked if they (a) owned a computer or tablet at home, (b) shared a computer or tablet at home, and (c) had an internet connection at home. These items were used to create the home ICT access index. This index was also developed through a principal component analysis. A higher score indicated that a student has sufficient ICT resources at home. Descriptive statistics for the selected variables are presented in Table 3.

The dimensions on frequency of ICT use were based on items that asked students how often you use a computer or tablet at home, school and other places. This was measured on a Likert scale of Every day, Once or twice a week, Once or twice a month, and Never or Almost never. The responses to this question were low, and so we dichotomised frequency at the different places into Yes $=1$, $\mathrm{No}=0$, Yes indicating that the student selected that they frequently use ICT and No for not using ICT frequently. 


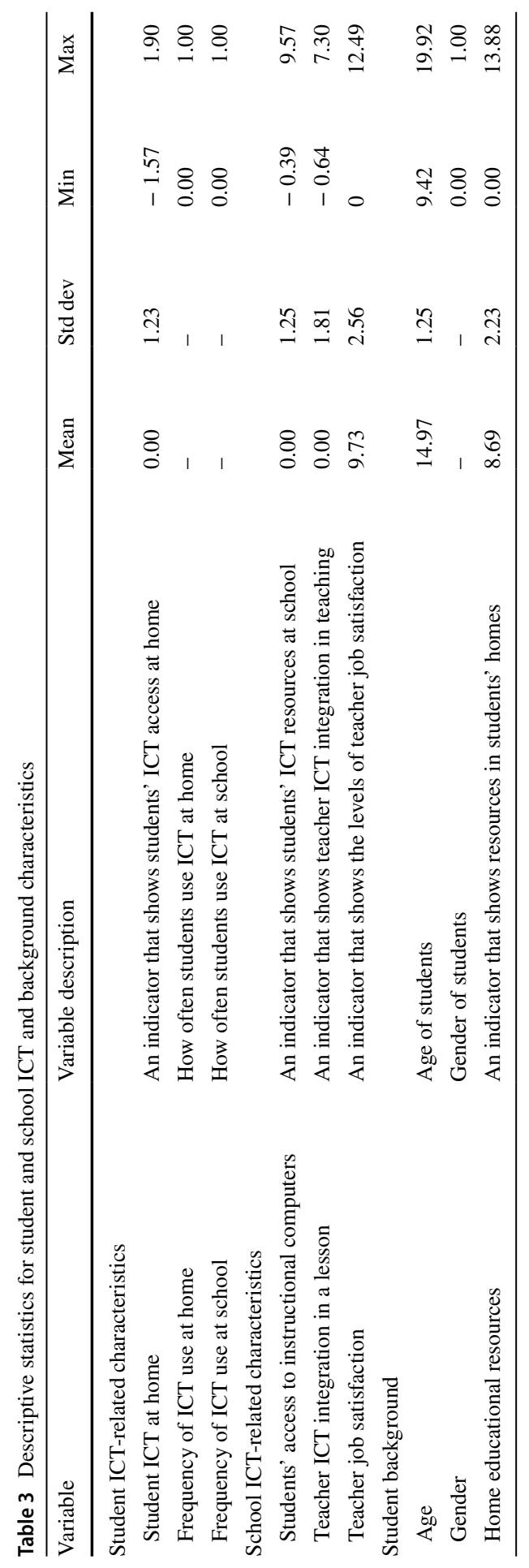




\section{Hierarchical linear modelling}

The analysis started with a null (unconditional) model that was developed to determine the extent to which observations within schools were correlated. The procedure involves the use of one-way analysis of variance (ANOVA) with random effects (Raudenbush and Bryk 2002). The null model (unconditional mean model) is used to partition the variance in the outcome variable (for example, mathematics scores) into within and between group components (Willms and Smith 2005). This provides a clear justification of estimating with HLM rather than other multiple regression techniques. The ICC, an indicator of the size of the clustering effect, was calculated to estimate the degree to which between school variances were represented in the total variation of the student model.

The second step included all of the control variables from the student level (home educational resources, student age and gender) in the model. The final step of the analysis included the ICT explanatory variables from student variables and school-level data. The final two-level HLM model is written as follows:

Level 1 model:

$$
\begin{aligned}
\text { Score }_{i j}= & \beta_{0 j}+\beta_{1 j} \times \text { ICThome }+\beta_{2 j} \times \text { ICTfrequsehome }+\beta_{3 j} \times \text { ICTfrequsesch }+\beta_{4 j} \times \text { age } \\
& +\beta_{5 j} \times \text { gender }+\beta_{5 j} \times \text { homeedures }+r_{i j}
\end{aligned}
$$

Level 2 model:

$$
\begin{gathered}
\beta_{0 j}=\gamma_{00}+\gamma_{01} \mathrm{ICTSCH}_{j}+\gamma_{02} \mathrm{ICTinteg}_{j}+\gamma_{04} \mathrm{TCH}_{j}+u_{0 j} \\
\beta_{1 j}=\gamma_{1 j} \quad \beta_{2 j}=\gamma_{2 j} \quad \beta_{3 j}=\gamma_{3 j} \\
\beta_{4 j}=\gamma_{4 j} \quad \beta_{5 j}=\gamma_{5 j}
\end{gathered}
$$

where $\operatorname{score}_{i j}$ is the mathematics score for student $i$ in school $j, \gamma_{00}$ is the mean mathematics score for all schools in the sample, $\gamma_{1 j}$ is the slope of ICT at home for student $i$ in school $j, \gamma_{2 j}$ is the slope of frequency in ICT use at home for student $i$ in school $j, \gamma_{3 j}$ is the slope of frequency in ICT use at school for student $i$ in school $j$, $\gamma_{4 j}$ is the slope of age for student $i$ in school $j, \gamma_{5 j}$ is the slope of gender for student $i$ in school $j, \gamma_{5 j}$ is the slope of home education resources for student $i$ in school $j$, $r_{i j}$ is a unique error associated with student $i$ in school $j, \gamma_{01}$ is the slope of students' access to instructional computers in each school, $\gamma_{02}$ is the slope of teacher ICT integration in each school, $\gamma_{03}$ is the slope of teacher job satisfaction in each school, and $u_{0 j}$ is a unique error to the intercept associated with school $j$ and has the variance $r_{00}$. 
Table 4 Intraclass coefficient for the null model
Mathematics achievement

\begin{tabular}{ll}
\hline School-level effect $\left(u_{0 j}\right)$ & 1968.90 \\
Student-level effect $\left(r_{i j}\right)$ & 6143.28 \\
ICC & $24 \%$ \\
\hline
\end{tabular}

\section{Results}

\section{Null (unconditional) model}

Table 4 shows the results from the null model, the purpose of this model is to calculate the ICC in order to examine whether the variance was significant between schools and students. The null model results show that there was a $24 \%$ variability, which could be attributed to schools (between school variance). This result further implies that, for this sample, further analyses with HLMs were necessary to examine the impacts of explanatory variables from the different levels.

\section{Random coefficient model for Grades 8 and 9 students}

In the second stage of the analysis, student-level control variables were incorporated into the model (see Table 5), with the aim of identifying the effectiveness of the selected explanatory variables. This section responds to the research question about the influence of student level background factors. All three student control variables were found to be significantly associated with students' mathematics achievement. In terms of gender difference, the results show that the gender gap is wider in

Table 5 A random coefficient model—student control variables

\begin{tabular}{|c|c|c|c|}
\hline \multirow[t]{2}{*}{ Fixed effects } & \multicolumn{2}{|c|}{ Mathematics achievement } & \multirow[t]{2}{*}{$t$ ratio } \\
\hline & Coefficient $(t)$ & Standard error & \\
\hline Achievement (intercept) & $674.75^{* * *}$ & 9.34 & 72.21 \\
\hline Age & $-19.32^{* * *}$ & 0.62 & -31.27 \\
\hline Gender & $2.26^{* * *}$ & 1.25 & 1.82 \\
\hline Home resources & $6.12^{* * *}$ & 0.38 & 16.17 \\
\hline Random effects & Variance component & Df & $\chi^{2}$ \\
\hline School-level effect $\left(u_{0 j}\right)$ & 1476.11 & 556 & 7832.21 \\
\hline Student-level effect $\left(r_{i j}\right)$ & 5467.44 & & \\
\hline$\%$ of reduced variance of $u_{0 j}$ & $25.02 \%$ & & \\
\hline$\%$ of reduced variance of $r_{i j}$ & $11.00 \%$ & & \\
\hline
\end{tabular}

$* p<0.05$

$* * p<0.01$

$* * * p<0.001$ 
mathematics performance: on average, male students achieved higher performance scores in mathematics compared to girls. The age variable was also significant, and it showed that older students lost 17.96 points in their mathematics achievement. The home educational resources index had a significant influence on achievement, with students with more educational resources achieving scores 6.12 points higher.

Comparing model 1 and the null model, it can be concluded that students' demographic factors do contribute to explaining the additional variations in student achievement. In model 1 with student controlling variables, the reduced variation was $25 \%$ at school level and $11 \%$ at student level.

\section{Random intercept full model with target predictors for students and schools}

In this third and final stage (model 2) of the analysis, all ICT-related variables from the student and school levels were included, along with the teacher job satisfaction indicator as a school control variable. These set of results respond to research question that relates to how access to and use of ICT in school and home settings influenced mathematics achievement. Comparing these results to model 1 in the second stage of the analysis, the inclusion of all ICT- related variables in Model 2

Table 6 The random intercept full model

\begin{tabular}{llll}
\hline Fixed effects & \multicolumn{2}{l}{ Mathematics achievement } & \multirow{2}{*}{ ratio } \\
\cline { 2 - 3 } & Coefficient $(t)$ & Standard error & \\
\hline Achievement (intercept) & $654.46^{* * * *}$ & 11.57 & 56.56 \\
Age & $-18.25^{* * *}$ & 0.60 & -30.18 \\
Gender & $1.10^{\mathrm{ns}}$ & 1.27 & 0.88 \\
Home resources & $4.82^{* * *}$ & 0.35 & 13.73 \\
Student ICT access at home & $8.59^{* * *}$ & 0.63 & 13.54 \\
Student frequency in using ICT at home & $-11.13^{* * *}$ & 1.25 & -8.91 \\
Student frequency in using ICT at school & $-3.57^{* * *}$ & 1.51 & -2.36 \\
Students' access to instructional computers & 4.80 & 2.97 & 1.61 \\
Teacher ICT integration in a lesson & $-2.98^{* *}$ & 1.33 & -2.23 \\
Teacher job satisfaction & $1.41^{* * *}$ & 0.65 & 2.15 \\
\hline Random effects & Variance component & Df & $\chi^{2}$ \\
\hline School-level effect $\left(u_{0 j}\right)$ & 1384.89 & 553 & 7523.04 \\
Student-level effect $\left(r_{i j}\right)$ & 5400.09 & & \\
$\%$ of reduced variance of $u_{0 j}$ & $29.66 \%$ & & \\
$\%$ of reduced variance of $r_{i j}$ & $12.09 \%$ & & \\
\hline
\end{tabular}

$n s$ not significant

$* p<0.05$

$* * p<0.01$

$* * * p<0.001$

$p<0.1$ 
accounted for approximately $30 \%$ of the variance at school level and up to $12 \%$ at student level. Table 6 presents the results of the full model (model 2) for mathematics achievement.

The school-level results show that school ICT-related characteristics had mixed effects. The indicator that showed teacher ICT use, or rather how teachers integrate ICT in teaching and learning, was negatively associated with student achievement. In this sample, a one-point increment in this indicator is associated with a 2.98-point decrease in the mathematics achievement score. This result could suggest that teachers are not well trained in ICT-related skills to use digital devices for instruction. In contrast, students' access to instructional computers was positively associated with student achievement; this positive association indicates that a one-point increment in the number of computers was associated with a 4.80-point higher achievement in mathematics. Teacher job satisfaction, as a control variable in the level 2 model, had a positive association with student achievement score.

At the student level, the home resources variable was found to have a consistent and significant positive influence on student achievement. This implies that students who had higher levels of home resources showed higher achievement indicators. In terms of ICT-related variables, two broad variables were examined on TIMSS surveys: access to ICT at home and frequency of using ICT either at home, school or some other place. In the analysis we used only frequency of using ICT at home and at school.

It was found that access to ICT at home index had a significantly positive association with student achievement, suggesting that students who owned or shared a computer at home and also had an internet connection, had higher achievement in mathematics. The positive association for the ICT at home indicator implies that a one-point improvement in the access to ICT at home increased students' mathematics scores by 8.59 points. The frequency of use of ICT both at home and at school had a significantly negative influence on student achievement. This suggested that students' time spent using ICT programs and software did not necessarily correlate with higher mathematics performance.

\section{Discussion}

The results from the multilevel models suggest that-as ICT advocates have asserted-ICT does matter to academic achievement; however, an important caveat is that whether it matters depends on how it is used (Wenglinsky 1998). The important contribution of this research is that it adds to the literature on how student- and school-level ICT access and usage influence student achievement in Africa. This has previously been an overlooked area in research and remains largely unexplored. By estimating a two-level HLM for a sample of four African countries, this research allows us to examine the relationship of ICT and education attainment. The findings are helpful for a better understanding of how and the extent to which school ICT development influences students' learning outcomes. Moreover, using TIMSS assessments, this study provides inclusivity in examining students' diverse ICT use and ICT influences on their achievement in Africa. This study included all four 
African countries that participated in TIMSS 2015, which previous studies have failed to do. Therefore, this study's findings have better generalisability and are of particular importance for policy makers, education researchers, and/or academicians.

\section{Influence of student background variables}

The overall findings in terms of the effects of student and school background variables are strong. Male students were found to have better learning outcomes than female students, which was consistent with the previous findings (Gumus and Atalmis 2011; Zhang and Liu 2016). Zhang and Liu (2016) explain that the gender gap in mathematics could be due to higher levels of anxiety, and less interest and confidence in mathematics. They suggest that additional support, like introducing interactive teaching strategies, could improve classroom environments (Liu and Wilson (2009). Consistent with previous research, home educational resources were strongly associated with learning outcomes (İnce and Gözütok 2018; Zhang and Liu 2016). The age variable was also strongly associated with achievement.

\section{Influence student ICT access and usage has on student achievement}

The evidence on student ICT access at home indicates that access generally has a positive association with learning outcomes. Consistent with previous studies, we can argue that students with access to ICT are associated with higher achievement scores. According to Kuhlemeier and Hemker (2007), students with access to ICT devices (for example, computers) at home have sufficient computer skills and better learning outcomes.

We can further argue that students' frequent use of ICT does not necessarily relate to better learning outcomes-although given that there is increasing investment in ICT in Africa, this could change over time. This result is consistent with previous research by Jager et al. (2008), Eickelmann et al. (2012), and Zhang and Liu (2016). The authors found that the intensity of ICT use at home was negatively associated with learning outcomes. In particular, Eickelmann et al. (2012) found that frequent computer use correlated with low achievement among students who participated in TIMSS 2007, because low achievers were likely to use computers at school to make up for the slow progress. Li and Ma (2010) explain that one possible interpretation of the lower student performance with increased use of ICT is that simple ICT skills such as word processing and creating spreadsheets are likely to help students in accomplishing important tasks.

Based on previous research, the association between the frequency of using ICT for schoolwork and learning outcomes remains inconclusive. According to the findings of Skryabin et al. (2015), it appears that there are mixed results concerning the intensity of ICT use and achievement. Skryabin et al. (2015) found differences between Grade 4 and Grade 8 students, where Grade 8 students with more frequent ICT usage in school were associated with lower learning outcomes. In contract, ICT usage among Grade 4 students had a positive influence on learning outcomes. 
Skryabin et al. (2015) also noted that students who frequently used ICT at home for school-related tasks were more likely to have better achievements.

In conclusion, the literature notes that ICT usage may affect narrow learning areas and may not have a strong and clear association with learning outcomes. Consequently, further exploration regarding the influence of frequency of ICT usage on learning outcomes is required.

\section{Influence school ICT indicators has on student achievement}

In this study, at the $10 \%$ significance level there is a positive association between students' access to instructional computers and mathematics performance. In the existing literature, Skryabin et al. (2015) showed that ICT use at school was positively associated with students' mathematics learning outcomes, which aligns with the research findings of Carrillo et al. (2011).

The result regarding the influence of teacher ICT integration in a lesson is significant and negatively associated with mathematics learning outcomes. A possible explanation for this result is that in most African schools, teachers' ICT integration does encounter a number of technological and attitudinal challenges. Such challenges are also referred to as extrinsic and intrinsic barriers (Xiao et al. 2019). Extrinsic challenges could include the lack of ICT support and training or sufficient resources in teaching and learning. Intrinsic challenges could include practices, attitudes and beliefs towards ICT use in teaching. Even if teachers believe that the use of ICT in teaching is beneficial, such as using PowerPoint slides for mathematics lessons, they could have limited ICT skills in delivering lessons with advanced ICT devices or mathematics programs.

Xiao et al. (2019) suggest that there is a lack of skills in modelling software and programming languages adapted for lessons such as mathematics. The negative correlation of teacher ICT integration could be because the use of ICT in a classroom environment is perhaps restricted to simple pedagogical practices, rather than effectively integrating ICT into the curriculum Aydin (2013). Hence, schools need to provide consistent support, such as school-based ICT training, to equip teachers with the necessary ICT skills. In addition, technical ICT support should be provided to address any difficulty in using ICT in the classroom (Xiao et al. 2019).

\section{Conclusion and implications for future research}

This study makes a new contribution to literature about the relationship between school ICT development, student ICT access and usage, and mathematics learning outcomes in an African context. The results show that student access to instructional computers during a lesson was a significant positive predictor of mathematics achievement. Recommendations for education policymakers should be to provide the required ICT infrastructure to schools, which is in line with the findings by Garegae (2015), who noted that teachers in the study schools in Botswana identified the lack of ICT resources as impeding their potential to use ICT in teaching. However, 
policymakers should also take heed of the findings by Tsayang et al. (2020), who argued that access to resources was not the only factor to promote ICT use, but that teachers had to possess the necessary skills and pedagogic insight in order for them to effectively use ICT for teaching and learning.

The result on teacher ICT integration indicated that teachers still lack current ICT skills to blend with pedagogy. Recommendations for educationists should be to bridge this gap by providing technical support and consistent ICT training to teachers. The need for ongoing ICT professional development is also noted by Bray and Tangney (2017) who emphasised skills development so as to use ICT in a more transformative and constructive manner.

Student ICT access at home also had a significant positive influence, indicating that students with ICT at home had more computer skills and were associated with higher learning outcomes. It is recommended that parents/guardians consider providing educational ICT devices and programs to students.

The frequency or intensity of ICT use both at home and school had negative associations with learning outcomes. This result remains contentious, according to findings from Tsayang et al. (2020), the increased frequency of use of ICT devices led to improved student performance, which also led to improved results. While this study engaged with limited literature that showed increased frequency results in improved achievement, there needs to be more research to investigate the levels at which the intensity of ICT use is to be accommodated.

Like all cross-sectional studies, this study also has limitations. In this study we only investigated associations between learning outcomes and variables of interest; therefore, no conclusions can be made on causal effect implications. Future research studies should consider experimental designs of such datasets to determine the cause-and-effect impacts of these variables. The second limitation relates to the lack of policy, infrastructure and national development ICT data; these kinds of data can provide more insight into how the national development of ICT affect learning outcomes.

Acknowledgements This research did not receive any specific grant from funding agencies in the public, commercial, or not-for-profit sectors. There are several HSRC staff who made significant contributions to putting together the data of this study. We thank the following individual for their assistance: Dr. Lolita Winnaar, senior research specialist at the Inclusive Economic Development research programme of the HSRC, provided the initial impetus for the study and nurtured it in many ways.

Author contributions $\mathrm{CN}$ conceptualised the study, designed the analysis, performed the analysis and writing of the manuscript. MM contributed to the conceptualisation of the study and writing of the manuscript.

Data availability The data that support the findings of this study are available in the International Association for the Evaluation of Educational Achievement data repository and can be accessed at https:// www.iea.nl/studies/iea/timss with reference number-TIMSS 2015. These data were derived from the following resources available in the public domain: TIMSS 2015 data at https://www.iea.nl/data-tools/ repository/timss

\section{Declarations}

Conflict of interest The authors declare that they have no conflict of interest. 
Ethical approval All procedures performed in studies involving human participants were in accordance with the ethical standards of the institutional and/or national research committee and with the $1964 \mathrm{Hel}$ sinki declaration and its later amendments or comparable ethical standards. The TIMSS study has ethical approval in all participating countries.

\section{References}

Adeosun O (2010) Quality basic education development in Nigeria: imperative for use of ICT. J Int Coop Educ 13(2):193-211

Agyei DD, Voogt J (2011) ICT use in the teaching of mathematics: implications for professional development of pre-service teachers in Ghana. Educ Inf Technol 16(4):423-439. https://doi.org/10.1007/ s10639-010-9141-9

Angrist J, Lavy V (2002) New evidence on classroom computers and pupil learning. Econ J 112(482):735-765. https://doi.org/10.1111/1468-0297.00068

Aydin S (2013) Teachers' perceptions about the use of computers in EFL teaching and learning: the case of Turkey. Comput Assist Lang Learn 26(3):214-233. https://doi.org/10.1080/09588221.2012. 654495

Banerjee AV, Cole S, Duflo E, Linden L (2007) Remedying education: evidence from two randomized experiments in India. Q J Econ 122(3):1235-1264. https://doi.org/10.1162/qjec.122.3.1235

Barakabitze AA, Kitindi EJ, Sanga C, Kibirige G, Makwinya N (2015) Exploring students' skills and attitudes on effective use of ICTs: case study of selected Tanzanian public secondary schools. Univers J Educ Res 3(6):407-425. https://doi.org/10.13189/ujer.2015.030609

Barrow L, Markman L, Rouse CE (2009) Technology's edge: the educational benefits of computer-aided instruction. Am Econ J Econ Pol 1(1):52-74. https://doi.org/10.2307/25760027

Berrado A, Darhmaoui H, El Asli A, Legrouri A, Loudiyi K, Messaoudi F, Smith K (2009) Measuring the impact of introducing ICT into the instruction of mathematics, physics, and earth and life sciences in the three Middle School Levels in Morocco. In: ICERI2009 proceedings, pp 2526-2531. Accessed 12 Jun 2021

Bray A, Tangney B (2017) Technology usage in mathematics education research: a systematic review of recent trends. Comput Educ 114:255-273

Carrillo PE, Onofa M, Ponce J (2011) Information technology and student achievement: evidence from a randomized experiment in Ecuador. IDB Working Paper Series (No. IDB-WP-223). Retrieved from https://www.econstor.eu/bitstream/10419/89010/1/IDB-WP-223.pdf. Accessed 08 Jul 2020

Comi SL, Argentin G, Gui M, Origo F, Pagani L (2017) Is it the way they use it? Teachers, ICT and student achievement. Econ Educ Rev 56:24-39. https://doi.org/10.1016/j.econedurev.2016.11.007

Eickelmann B, Drossel K, Wendt H, Bos W (2012) ICT-use in primary schools and children's mathematics achievement-a multi-level approach to compare educational systems through an international lens with TIMSS data. In: Joint AARE APERA international conference, WERA focal meeting, Sydney. Retrieved from https://kw.uni-paderborn.de/fileadmin/fakultaet/Institute/erziehungswisse nschaft/Schulpaedagogik/PDF/WERA_2012_Eickelmann_et_al..pdf. Accessed 11 Aug 2020

Erdogdu F, Erdogdu E (2015) The impact of access to ICT, student background and school/home environment on academic success of students in Turkey: an international comparative analysis. Comput Educ 82:26-49. https://doi.org/10.1016/j.compedu.2014.10.023

Fajebe AA, Best ML, Smyth TN (2013) Is the one laptop per child enough? Viewpoints from classroom teachers in Rwanda. Inf Technol Int Dev 9(3):29-42

Garegae KG (2015) Issues and concerns about the integration of ICT into the teaching and learning of mathematics in Africa: Botswana case. In: Sung JC (ed) Selected regular lectures from the 12th international congress on mathematical education. Springer, Cham, pp 187-202

Goldstein H (2011) Multilevel statistical models, 4th edn. Wiley, West Sussex

Graham MA, Stols G, Kapp R (2020) Teacher practice and integration of ICT: why are or aren't South African teachers using ICTs in their classrooms. Int J Instr 13(2):749-766

Gumus S, Atalmis EH (2011) Exploring the relationship between purpose of computer usage and reading skills of Turkish students: evidence from PISA 2006. Turk Online J Educ Technol 10(3):129-140

Hanushek EA (1979) Conceptual and empirical issues in the estimation of educational production functions. J Hum Resour 14(3):351-388. https://doi.org/10.2307/145575 
Hox JJ, Moerbeek M, Van de Schoot R (2017) Multilevel analysis: techniques and applications, 3rd edn. Routledge, New York

Hu X, Gong Y, Lai C, Leung FKS (2018) The relationship between ICT and student literacy in mathematics, reading, and science across 44 countries: a multilevel analysis. Comput Educ 125:1-13. https://doi.org/10.1016/j.compedu.2018.05.021

Hudson R, Porter A (2010) ICT use to improve mathematics learning in secondary schools. Paper presented at the ACEC2010: Digital diversity. Conference proceedings of the Australian Computers in Education Conference. Melbourne, Australia: ACEC. Retrieved from https://acec2010.info/propo sal/970/ict-use-improve-mathematicslearning-secondary-schools.

International Telecommunication Union (2015) Measuring the Information Society Report 2015. Retrieved from ITU, Geneva. https://www.itu.int/en/ITU-D/Statistics/Documents/publications/ misr2015/MISR2015-ES-E.pdf. Accessed 05 Jan 2021

International Telecommunication Union (2020) Measuring digital development: facts and figures, 2020. Retrieved from Geneva https:/www.itu.int/en/ITU-D/Statistics/Documents/facts/Facts Figures2020.pdf. Accessed 05 Jan 2021

İnce M, Gözütok FD (2018) Effect of parental education and home educational resources to students' results of PISA reading skills test. Elem Educ Online 17(2):947

Jager C, Bos J, Velde R (2008) Impact of ICT on production of goods and services: measuring the impact of ICT on education. The Linked World: Working Paper Series. Accessed 11 Jul 2020

Kuhlemeier H, Hemker B (2007) The impact of computer use at home on students' internet skills. Comput Educ 49(2):460-480. https://doi.org/10.1016/j.compedu.2005.10.004

Lamdin DJ (1996) Evidence of student attendance as an independent variable in education production functions. J Educ Res 89(3):155-162. https://doi.org/10.1080/00220671.1996.9941321

Lee VE (2000) Using hierarchical linear modeling to study social contexts: the case of school effects. Educ Psychol 35(2):125-141. https://doi.org/10.1207/S15326985EP3502_6

Li Q, Ma X (2010) A meta-analysis of the effects of computer technology on school students' mathematics learning. Educ Psychol Rev 22(3):215-243. https://doi.org/10.1007/s10648-010-9125-8

Liu OL, Wilson M (2009) Gender differences in large-scale math assessments: PISA trend 2000 and 2003. Appl Meas Educ 22(2):164-184. https://doi.org/10.1080/08957340902754635

Ndlovu M, Ramdhany V, Spangenberg ED, Govender R (2020) Preservice teachers' beliefs and intentions about integrating mathematics teaching and learning ICTs in their classrooms. ZDM 52(7):1365-1380. https://doi.org/10.1007/s11858-020-01186-2

Ponelis SR, Holmner MA (2015) ICT in Africa: enabling a better life for all. Inf Technol Dev 21(1):111. https://doi.org/10.1080/02681102.2014.985521

Raudenbush SW, Bryk AS (2002) Hierarchical linear models: applications and data analysis methods, 2nd edn, vol 1. Sage publications, London

Rubagiza J, Were E, Sutherland R (2011) Introducing ICT into schools in Rwanda: educational challenges and opportunities. Int J Educ Dev 31(1):37-43. https://doi.org/10.1016/j.ijedudev.2010. 06.004

Skryabin M, Zhang J, Liu L, Zhang D (2015) How the ICT development level and usage influence student achievement in reading, mathematics, and science. Comput Educ 85:49-58. https://doi. org/10.1016/j.compedu.2015.02.004

Spiezia V (2011) Does computer use increase educational achievements? Student-level evidence from PISA. OECD J 2010(1):1-22

Tsayang G, Batane T, Majuta A (2020) The impact of interactive smart boards on students' learning in secondary schools in Botswana: a students' perspective. Int J Educ Dev Using Inf Commun Technol 16(2):22-39

Umugiraneza O, Bansilal S, North D (2018) Exploring teachers' use of technology in teaching and learning mathematics in KwaZulu-Natal schools. Pythagoras 39(1):1-13

UNESCO (2018) ICT transforming education in Africa. Retrieved from http://www.unesco.org/new/ fileadmin/MULTIMEDIA/FIELD/Nairobi/unescokfitprojectupdateapril2018.pdf. Accessed 06 Jan 2021

UNESCO-UIS (2015) Information and communication technology (ICT) in education in Sub-Saharan Africa: a comparative analysis of basic e-readiness in schools. UNESCO Institute for Statistics, Montreal

UNESCO-UIS (2016) ICT in education statistics: shifting from regional reporting to global monitoring: progress made, challenges encountered, and the way forward. Background paper prepared for the 2016 Global education monitoring report, Education for people and planet: creating 
sustainable futures for all. Retrieved from https://unesdoc.unesco.org/ark:/48223/pf0000245572. Accessed 18 Aug 2020

Wenglinsky H (1998) Does it compute? The relationship between educational technology and student achievement in mathematics. (ED 425 191). Retrieved from http://files.eric.ed.gov/fulltext/ED425 191.pdf. Accessed 11 Sep 2020

Willms JD, Smith T (2005) A manual for conducting analyses with data from TIMSS and PISA. Report prepared for UNESCO Institute for Statistics

Wittwer J, Senkbeil M (2008) Is students' computer use at home related to their mathematical performance at school? Comput Educ 50(4):1558-1571. https://doi.org/10.1016/j.compedu.2007.03.001

Woltman H, Feldstain A, MacKay JC, Rocchi M (2012) An introduction to hierarchical linear modeling. Tutor Quant Methods Psychol 8(1):52-69

Xiao Y, Liu Y, Hu J (2019) Regression analysis of ICT impact factors on early adolescents' reading proficiency in five high-performing countries. Front Psychol 10:1646. https://doi.org/10.3389/fpsyg. 2019.01646

Zhang D, Liu L (2016) How does ICT use influence students' achievements in math and science over time? Eurasia J Math Sci Technol Educ 12(9):2431-2449. https://doi.org/10.12973/eurasia.2016. $1297 \mathrm{a}$ 